\title{
Facial Nerve Paralysis due to a Pleomorphic Adenoma with the Imaging Characteristics of a Facial Nerve Schwannoma
}

\author{
Marc-Elie Nader $^{1}$ Diana Bell ${ }^{2}$ Erich M. Sturgis ${ }^{1} \quad$ Lawrence E. Ginsberg $^{3}$ Paul W. Gidley ${ }^{1}$ \\ ${ }^{1}$ Department of Head and Neck Surgery, UT MD Anderson Cancer \\ Center, Houston, Texas, United States \\ 2 Department of Pathology, UT MD Anderson Cancer Center, Houston, \\ Texas, United States \\ Address for correspondence Paul W. Gidley, MD, Department of Head \\ and Neck Surgery, Unit 1445, The University of Texas MD Anderson \\ Cancer Center, 1515 Holcombe Blvd., Houston, TX 77030, United \\ States (e-mail: pwgidley@mdanderson.org).
}

${ }^{3}$ Department of Diagnostic Radiology, UT MD Anderson Cancer Center, Houston, Texas, United States

J Neurol Surg Rep 2014;75:e84-e88.

\begin{abstract}
Keywords

- pleomorphic adenoma

- facial nerve paralysis

- Schwannoma

- benign

- salivary gland tumor

Background Facial nerve paralysis in a patient with a salivary gland mass usually denotes malignancy. However, facial paralysis can also be caused by benign salivary gland tumors.

Methods We present a case of facial nerve paralysis due to a benign salivary gland tumor that had the imaging characteristics of an intraparotid facial nerve schwannoma. Results The patient presented to our clinic 4 years after the onset of facial nerve paralysis initially diagnosed as Bell palsy. Computed tomography demonstrated filling and erosion of the stylomastoid foramen with a mass on the facial nerve. Postoperative histopathology showed the presence of a pleomorphic adenoma. Facial paralysis was thought to be caused by extrinsic nerve compression.

Conclusions This case illustrates the difficulty of accurate preoperative diagnosis of a parotid gland mass and reinforces the concept that facial nerve paralysis in the context of salivary gland tumors may not always indicate malignancy.
\end{abstract}

\section{Introduction}

Facial nerve paralysis in a patient with a parotid mass classically suggests a malignant process. The status of the seventh cranial nerve not only is considered a reliable indicator of malignancy but also correlates with the histologic grade and the postoperative prognosis. ${ }^{1,2}$ Only a few reports in the literature have described facial nerve paralysis due to benign parotid tumors. We report the first case to our knowledge of facial nerve paralysis due to a benign primary parotid tumor with the imaging characteristics of an intraparotid facial nerve schwannoma.

\section{Case Report}

A 71-year-old woman was referred to our clinic with a 4-year history of facial nerve paralysis on the left side. Her family first noted lower left facial asymmetry in 2008 , and the patient was initially diagnosed with a transient ischemic attack. The facial weakness progressively worsened and eventually resulted in complete paralysis of the left side of the face. At that point, the patient was given a diagnosis of Bell palsy. The patient underwent lower eyelid surgery for ectropion, epiphora, and dry eye. The relevant medical history included previous skin resections for multiple cutaneous malignancies. received

August 15, 2013

accepted after revision

December 6, 2013

published online

April 17, 2014
DOI http://dx.doi.org/

$10.1055 / \mathrm{s}-0034-1368149$.

ISSN 2193-6358. (c) 2014 Georg Thieme Verlag KG

Stuttgart · New York
License terms

(c) $(1) \$$ 

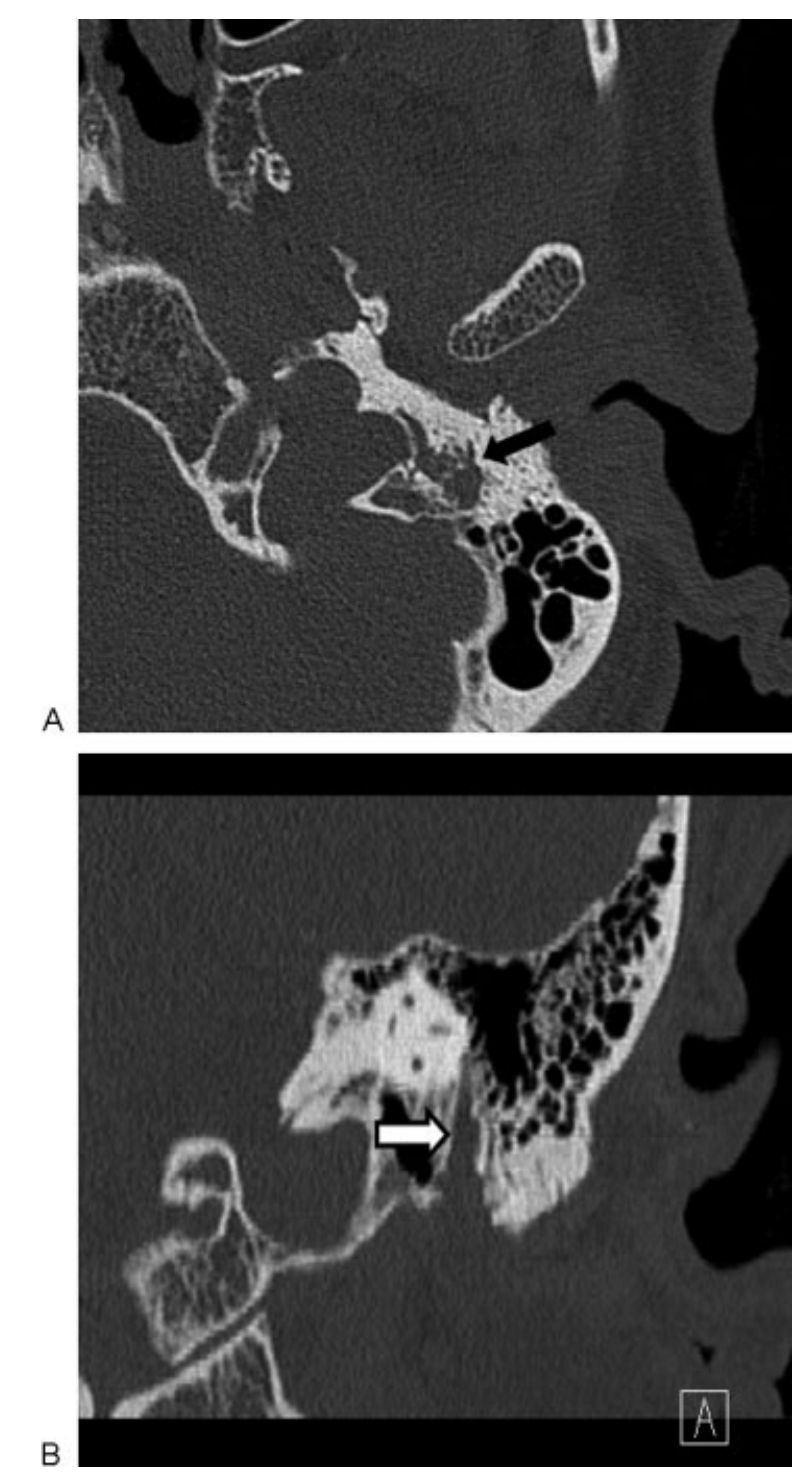

Fig. 1 (A) Axial and (B) coronal computed tomographic scans, in bone algorithm, illustrating enlargement and osseous erosion in the region of the stylomastoid foramen (arrows).

On physical examination, grade 5/6 left facial paresis was noted with minimal movement at the oral commissure. The remainder of the neurologic examination was normal. The left eye demonstrated epiphora and mild irritation. No masses of the parotid gland or the neck were detected on palpation, and there was no bulge or displacement of the tonsillar pharyngeal wall. The otologic examination was normal. Audiometry showed bilateral mild to moderately severe downsloping sensorineural hearing loss with excellent discrimination scores. High-resolution computed tomography demonstrated erosion of the stylomastoid foramen on the left side and showed that the stylomastoid foramen on the left side was filled with a mass on the left facial nerve that measured $8 \mathrm{~mm}$ in the greatest dimension (-Fig. 1). Magnetic resonance imaging confirmed an $8 \times 10-\mathrm{mm}$ lesion at the stylomastoid foramen that was enhancing after infusion of contrast material (-Fig. 2). These imaging findings were consistent with a possible facial nerve schwannoma. Other

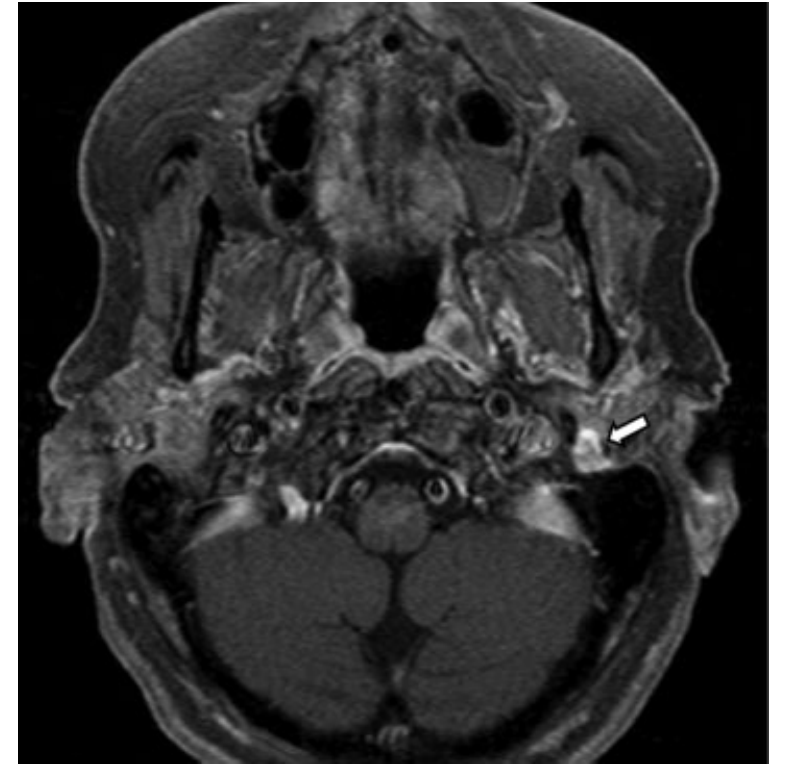

Fig. 2 Axial T1, contrast-enhanced, fat-suppressed magnetic resonance image showing an enhancing mass at the stylomastoid foramen (arrow).

disorders to be considered in the differential diagnosis included primary parotid gland tumors, either benign or malignant, perineural spread of cutaneous malignancy, or facial nerve hemangioma. The differential diagnosis is greatly limited considering the long-standing nature of her paralysis, the location of facial nerve enhancement, a normal ear examination, and overall good health.

Operative findings included fusiform enlargement of the stylomastoid portion of the facial nerve extending for $13 \mathrm{~mm}$ proximally. The vertical portion of the facial nerve was decompressed following a canal-intact mastoidectomy. The facial nerve was followed to the stylomastoid foramen, which was enlarged by the tumor. A superficial parotidectomy was performed, and the affected portion of the facial nerve was included in the specimen. A biopsy of soft tissue surrounding the facial nerve at the stylomastoid foramen was interpreted by the pathologist as suggestive of schwannoma on frozen section analysis. Normal nerve was encountered proximally in the mastoid and at the level of the pes anserinus. Neural reconstruction was performed with a sural nerve cable graft. Final histologic examination revealed encasement of the facial nerve and its arborizing branches by salivary mixed tumor with chondroid and epithelial components compatible with pleomorphic adenoma without any evidence of schwannoma or malignancy (-Fig. 3).

\section{Discussion}

The differential diagnosis of facial paralysis in a patient with a tumor commonly includes primary facial nerve tumor, malignant tumor of the parotid gland or metastatic skin cancer, and glomus jugulare or other temporal bone neoplasm; pleomorphic adenomas are rarely included. In patients with salivary gland tumors, facial nerve paralysis, local 


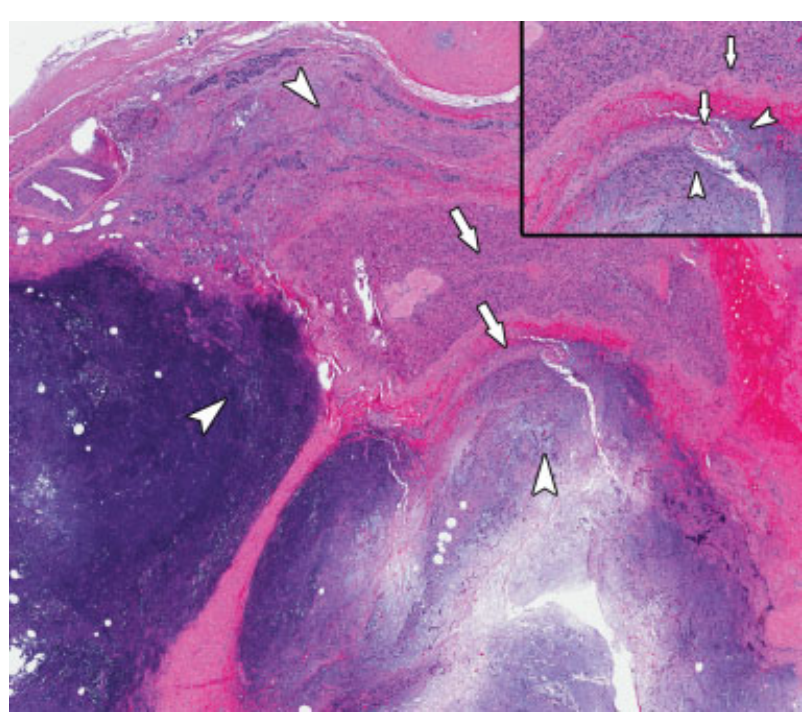

Fig. 3 Encasement of large-caliber nerve and arborizing branches (arrows) by salivary mixed tumor with chondroid and epithelial components (arrowheads), consistent with pleomorphic adenoma (hematoxylin-eosin; low-power view). Inset: Small nerve branch embedded in pleomorphic adenoma (hematoxylin-eosin; high-power view).

invasion, and the presence of metastatic lesions form a triad that classically indicates a malignant process. The presence of facial nerve palsy also seems to be associated with a poorer prognosis. A large multi-institutional study performed by Eneroth et al in 1977 revealed that $14 \%$ of patients (145 of
1029) with salivary gland malignancies presented with facial nerve weakness. Patients with facial nerve weakness had a poorer prognosis, with a 5-year survival rate of only $9 \% .^{3}$ In 2011, Wierzbicka et al reported an incidence of facial nerve weakness of $31 \%$ of patients (32 of 103 ) with parotid gland malignancies. In this series, patients with facial nerve weakness had a 3 -year disease-free survival rate of $45 \%$, compared with $88 \%$ in those without any facial nerve paresis. ${ }^{2}$

Although strong evidence in the literature supports the association of facial nerve dysfunction with parotid gland malignancy, this clinical finding should not be considered pathognomonic for malignant disease. Although several studies analyzing large series of patients with parotid tumors reported the occurrence of facial palsy only in patients with malignancy, ${ }^{4-6}$ facial palsy due to benign parotid gland tumors has also been reported. A comprehensive review of the literature revealed 17 such cases ${ }^{7-22}$ (-Table 1 ). The present case differs from the ones already discussed in the literature in two aspects. First, it was the smallest benign parotid tumor causing facial nerve palsy with the exception of a $0.5-\mathrm{cm}$ tumor in a 9-year old boy reported by Mamakos et al. ${ }^{10}$ Second, the present case is the first in which a benign parotid tumor causing facial palsy was initially thought to originate from the facial nerve on the basis of preoperative imaging and frozen-section analysis.

To our knowledge, the case that we describe here is the first reported case of facial palsy caused by a pleomorphic adenoma that had the imaging characteristics of an intraparotid schwannoma. The diagnosis of schwannoma was suggested by preoperative imaging findings and was initially

Table 1 Reported cases of facial palsy due to benign parotid tumors

\begin{tabular}{|c|c|c|c|c|}
\hline Study & Age, y/Sex & Histology & Size, $\mathrm{cm}$ & Presumed mechanism \\
\hline Ward and Hendrick ${ }^{7}$ & $41 / \mathrm{F}$ & Pleomorphic adenoma & $>10$ & Hemorrhage/stretch \\
\hline La Ventura et $\mathrm{al}^{8}$ & $70 / F$ & Pleomorphic adenoma & 2.5 & Stretch \\
\hline 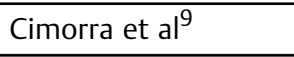 & $55 / \mathrm{M}$ & Pleomorphic adenoma & 3 & Stretch \\
\hline Mamakos et al ${ }^{10}$ & $9 / \mathrm{M}$ & Pleomorphic adenoma & 0.5 & Temporal bone invasion/compression \\
\hline Papangelou et al $^{11}$ & $76 / \mathrm{M}$ & Oncocytoma & 2.5 & Stretch \\
\hline Lesser and Spector $^{12}$ & $75 / \mathrm{M}$ & Warthin tumor & 5 & Inflammation/stretch \\
\hline Whillis et $\mathrm{al}^{13}$ & $60 / F$ & Warthin tumor & 6 & Inflammation/stretch \\
\hline DeLozier et al $^{14}$ & $72 / \mathrm{F}$ & Warthin tumor & 4 & Inflammation/stretch \\
\hline Blevins et al $^{15}$ & $\begin{array}{l}59 / \mathrm{F} \\
62 / \mathrm{M}\end{array}$ & $\begin{array}{l}\text { Pleomorphic adenoma } \\
\text { Pleomorphic adenoma }\end{array}$ & $\begin{array}{l}3 \\
2\end{array}$ & $\begin{array}{l}\text { Temporal bone invasion/compression } \\
\text { Temporal bone invasion/compression }\end{array}$ \\
\hline Newman et $a^{16}$ & $70 / \mathrm{F}$ & Warthin tumor & 5 & Inflammation \\
\hline Koide et al ${ }^{17}$ & $79 / \mathrm{M}$ & Warthin tumor & 6 & Compression/ischemia \\
\hline Srinivasan et al ${ }^{18}$ & $62 / \mathrm{M}$ & Lipoma & 4 & Unknown \\
\hline Berry et al ${ }^{19}$ & $82 / \mathrm{F}$ & Warthin tumor & Not reported & Unknown \\
\hline Maini and Osborne ${ }^{20}$ & $72 / \mathrm{M}$ & Warthin tumor & 3.5 & Inflammation or ischemia \\
\hline Marioni et al ${ }^{21}$ & $86 / \mathrm{M}$ & Warthin tumor & 6 & Unknown \\
\hline Woodhouse et $\mathrm{al}^{22}$ & $69 / \mathrm{M}$ & Warthin tumor & 6 & Compression/ischemia or Bell palsy \\
\hline Present case & $71 / \mathrm{F}$ & Pleomorphic adenoma & 1 & Temporal bone invasion/compression \\
\hline
\end{tabular}


thought to be confirmed on intraoperative frozen-section analysis. Also, the progression of the facial weakness over a period of 4 years without other signs of malignancy did not suggest a cancerous etiology. However, as demonstrated by this case and discussed by other authors, ${ }^{23}$ imaging characteristics of intraparotid schwannomas are not specific, and an accurate preoperative diagnosis may be difficult.

In the present case, the preoperative imaging showed a smooth mass centered on the facial nerve with erosion of the stylomastoid foramen with enhancement in the vertical segment of the intratemporal facial nerve, which led us initially to suspect a facial nerve schwannoma rather than a pleomorphic adenoma. On computed tomography, an intraparotid schwannoma can appear as a smooth, circumscribed intraparotid lesion, with possible dilatation of the stylomastoid foramen and fallopian canal in case of intratemporal extension. On gadolinium-enhanced magnetic resonance imaging, intraparotid schwannomas are isointense to hypointense on T1 and isointense to hyperintense on T2, with strong contrast agent uptake. ${ }^{23}$ However, the imaging patterns of intraparotid schwannomas can be similar to those of other, more common benign parotid tumors, such as pleomorphic adenoma. Indeed, pleomorphic adenomas also present on computed tomography as smooth, well-delineated masses. Nodularity is sometimes found on the outer surface, and larger tumors may be more heterogeneous. ${ }^{24}$ On magnetic resonance imaging, pleomorphic adenomas present as wellcircumscribed masses hypointense on T1, hyperintense on T2, and with heterogeneous enhancement with gadolinium. ${ }^{25}$

Accurate preoperative diagnosis helps the surgeon determine the optimal therapeutic approach. However, as illustrated by this case, accurate preoperative diagnosis is not always possible. There are differences between the surgical treatment of pleomorphic adenomas and the surgical treatment of intraparotid facial nerve schwannomas. The recurrence rate after gross resection of intraparotid facial nerve schwannomas seems to be negligible if at all existent. ${ }^{23}$ However, when a pleomorphic adenoma is resected, a cuff of normal tissue must be included to avoid recurrence due to failure to remove the pseudopod-like extensions of tumor. ${ }^{26,27}$ In the present case, a portion of the facial nerve was resected along with the mass. This decision to resect the facial nerve was facilitated by the long-standing facial nerve paralysis. Negative margins were confirmed, and nerve grafting was performed. Thus the surgical treatment would not have been different even if we had initially suspected a pleomorphic adenoma rather than a facial nerve schwannoma.

This case raises some additional points. The duration of facial paralysis was central to our diagnosis and treatment planning. If this patient had presented with an acute onset of facial weakness and imaging suggesting schwannoma, we would have considered facial nerve decompression. The decision to perform an intraoperative biopsy would then have depended on surgical findings at time of decompression with the decision to sacrifice the nerve and perform nerve grafting predicated on the pathologic findings and the degree of facial weakness. Further, even though an incisional biopsy on a pleomorphic adenoma might have produced tumor spillage, the patient did not receive any postoperative radiation because we reserve this treatment modality for proven multifocal recurrence.

The presented case illustrates that facial palsy is not always an indicator of malignancy. This case also highlights the difficulty of accurate preoperative and even intraoperative diagnosis of salivary gland tumors.

\section{Acknowledgment}

We wish to thank Stephanie Deming for her help in the final editorial review of this case report.

\section{References}

1 Eneroth CM. Facial nerve paralysis. A criterion of malignancy in parotid tumors. Arch Otolaryngol 1972;95(4):300-304

2 Wierzbicka M, Kopeć T, Szyfter W, Kereiakes T, Bem G. The presence of facial nerve weakness on diagnosis of a parotid gland malignant process. Eur Arch Otorhinolaryngol 2012;269(4): 1177-1182

3 Eneroth CM, Andreasson L, Beran M, et al. Preoperative facial paralysis in malignant parotid tumours. ORL J Otorhinolaryngol Relat Spec 1977;39(5):272-277

4 Frazell EL. Clinical aspects of tumors of the major salivary glands. Cancer 1954;7(4):637-659

5 Beahrs OH, Woolner LB, Carveth SW, Devine KD. Surgical management of parotid lesions. Review of seven hundred sixty cases. Arch Surg 1960;80:890-904

6 Bardwill JM. Tumors of the parotid gland. Am J Surg 1967;114(4): 498-502

7 Ward GE, Hendrick JW. Tumors of the Head and Neck. Baltimore, MD: Williams \& Wilkins; 1950:388-389

8 LaVenuta F, Flynn WF, Moore JA. Facial nerve paralysis secondary to benign parotid tumor. Arch Otolaryngol 1969;90(5):603-604

9 Cimorra GA, Ferreira V, Martinez-Tello FJ. Spontaneous facial nerve paralysis associated with an ipsilateral benign parotid tumor. Case report. Plast Reconstr Surg 1972;50(5):523-525

10 Mamakos MS, Wright R, Earle AS. Facial palsy in a child with a parotid tumor. Int Surg 1977;62(9):468-469

11 Papangelou LP, Alkalai K, Kyrillopoulou M. Facial nerve paralysis in the presence of a benign parotid tumor. Arch Otolaryngol 1982; 108(7):458-459

12 Lesser RW, Spector JG. Facial nerve palsy associated with Warthin's tumor. Arch Otolaryngol 1985;111(8):548-549

13 Whillis D, Goepel JR, Shorthouse AJ. Facial paralysis due to a benign parotid tumour. Br J Surg 1989;76(1):95

14 DeLozier HL, Spinella MJ, Johnson GD. Facial nerve paralysis with benign parotid masses. Ann Otol Rhinol Laryngol 1989;98(8 Pt 1): 644-647

15 Blevins NH, Jackler RK, Kaplan MJ, Boles R. Facial paralysis due to benign parotid tumors. Arch Otolaryngol Head Neck Surg 1992; 118(4):427-430

16 Newman L, Loukota RA, Bradley PF. An infarcted Warthin's tumour presenting with facial weakness. Br J Oral Maxillofac Surg 1993; 31(5):311-312

17 Koide C, Imai A, Nagaba A, Takahashi T. Pathological findings of the facial nerve in a case of facial nerve palsy associated with benign parotid tumor. Arch Otolaryngol Head Neck Surg 1994;120(4): 410-412

18 Srinivasan V, Ganesan S, Premachandra DJ. Lipoma of the parotid gland presenting with facial palsy. J Laryngol Otol 1996;110(1): 93-95 
e88 Facial Nerve Paralysis Nader et al.

19 Berry MG, Brown AA, Lee PH, Kangesu L. Acute facial-nerve paralysis with parotid adenolymphoma. Br J Plast Surg 2001;54(5):454-456

20 Maini S, Osborne JE. Ischaemic necrosis and facial palsy in Warthin's tumour of the parotid gland. Auris Nasus Larynx 2002;29(1):99-101

21 Marioni G, de Filippis C, Gaio E, Iaderosa GA, Staffieri A. Facial nerve paralysis secondary to Warthin's tumour of the parotid gland. J Laryngol Otol 2003;117(6):511-513

22 Woodhouse NR, Gok G, Howlett DC, Ramesar K. Warthin's tumour and facial nerve palsy: an unusual association. Br J Oral Maxillofac Surg 2011;49(3):237-238

23 Gross BC, Carlson ML, Moore EJ, Driscoll CL, Olsen KD. The intraparotid facial nerve schwannoma: a diagnostic and management conundrum. Am J Otolaryngol 2012;33(5):497-504
24 Brunese L, Ciccarelli R, Fucili S, et al. Pleomorphic adenoma of parotid gland: delayed enhancement on computed tomography. Dentomaxillofac Radiol 2008;37(8):464-469

25 Habermann CR, Arndt C, Graessner J, et al. Diffusion-weighted echo-planar MR imaging of primary parotid gland tumors: is a prediction of different histologic subtypes possible? AJNR Am J Neuroradiol 2009;30(3):591-596

26 Stennert E, Guntinas-Lichius O, Klussmann JP, Arnold G. Histopathology of pleomorphic adenoma in the parotid gland: a prospective unselected series of 100 cases. Laryngoscope 2001;111(12): 2195-2200

27 Witt RL. The significance of the margin in parotid surgery for pleomorphic adenoma. Laryngoscope 2002;112(12):2141-2154 